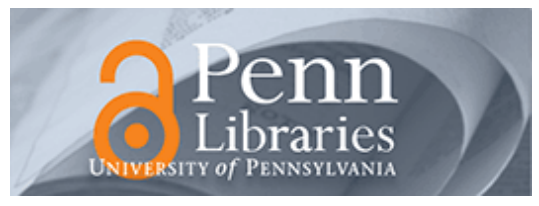

University of Pennsylvania ScholarlyCommons

$1-2014$

\title{
R\&D Production Team Composition and Firm-Level Innovation
}

Vikas A. Aggarwal

University of Pennsylvania

David Hsu

University of Pennsylvania

Andy Wu

University of Pennsylvania

Follow this and additional works at: https://repository.upenn.edu/mgmt_papers

Part of the Management Sciences and Quantitative Methods Commons

\section{Recommended Citation}

Aggarwal, V. A., Hsu, D., \& Wu, A. (2014). R\&D Production Team Composition and Firm-Level Innovation. Academy of Management Proceedings, http://dx.doi.org/10.5465/AMBPP.2014.12314abstract

This paper is posted at ScholarlyCommons. https://repository.upenn.edu/mgmt_papers/237

For more information, please contact repository@pobox.upenn.edu. 


\title{
R\&D Production Team Composition and Firm-Level Innovation
}

\begin{abstract}
We examine the relationship between firms' within- and across-inventor team composition and firm-level innovation. An empirical regularity in the prior literature on inventor teams is that diversity, as measured by factors such as prior technology experience, can positively influence a team's innovative performance. The literature has remained silent, however, on the issue of how an inventor team's presence within the broader context of the firm influences the firm's aggregate innovative output. This question has implications for understanding the optimal allocation of production-related human capital, particularly in resource-constrained start-up environments. We assemble a panel dataset of start-up biotechnology firms founded between 1980 and 2000, tracked from founding through 2009, to develop and test hypotheses regarding the link between team structure and firm-level forward patent citations. We find that innovation is best promoted with greater across-team diversity and lower within-team diversity. This result is moderated by the firm's product development stage, the complexity of its technology environment, joint experience among the firm's inventors, and the degree to which production team structure is modulated over time. We find important differences in the results when running a parallel analysis at the patent team-level, which provides further evidence in support of the idea that within- firm production team organization structure influences firm-level innovation output. An implication is that prior results in the literature regarding knowledge production teams may not generalize to the firm-level of analysis.

\section{Disciplines}

Management Sciences and Quantitative Methods
\end{abstract}




\title{
R\&D PRODUCTION TEAM ORGANIZATION AND FIRM-LEVEL INNOVATION
}

\author{
Vikas A. Aggarwal, David H. Hsu \& Andy Wu *
}

January 2015

\begin{abstract}
How should a firm organize the diversity of technological experience contained within its base of inventors when firm-level innovation output is a key performance consideration? We investigate the innovation implications of alternate firm-level approaches to organizing such diversity. Building on the knowledge-based view and organization design literatures, we examine the effects of across-team and within-team technical experience diversity on firm-level innovation output. Our framework suggests these alternate managerial choices involve trading off knowledge recombination benefits and coordination costs. Using a panel dataset of biotechnology start-ups observed from their founding date onwards, we find that across-team diversity results in greater firm-level innovation benefits as compared to within-team diversity. We also find evidence that collaborative experience and combinatorial novelty moderate this effect, further supporting our proposed framework.
\end{abstract}

Keywords: Knowledge-based view; organization design; innovation; knowledge recombination; coordination costs

\footnotetext{
*Email addresses: vikas.aggarwal@insead.edu; dhsu@wharton.upenn.edu; and andywu@wharton.upenn.edu. The authors thank Martine Haas, Henning Piezunka, and participants at the 2014 Academy of Management Annual Meeting, 2014 Strategic Management Society Annual International Conference, and 2014 London Business School TADC, for valuable comments; Sean Nicholson and Simon Wakeman for providing biotechnology product and alliance data; and Charles Du and Andrea Contigiani for excellent research assistance. The authors gratefully acknowledge funding from the INSEAD-Wharton Center for Global Research and Education and the Mack Institute for Innovation Management.
} 


\section{INTRODUCTION}

Collaborative (rather than solo) production of knowledge by multiple inventors inside a firm has become an important source of firm-level innovation output (e.g., Wuchty, Jones and Uzzi, 2007). The shift toward this form of knowledge production has been driven in part by the increasingly high investment needed for inventors to remain at the forefront of a particular field (Jones, 2009). A team-based approach addresses the issue of narrower and more specialized inventor profiles, with recent empirical work suggesting that teams are more likely than solo inventors to produce "breakthrough" inventions (Singh and Fleming, 2010). The importance of this approach to innovation resonates with popular accounts of business history. Tracing the roots of the digital revolution from the mid $-19^{\text {th }}$ century through the present day for instance, Isaacson (2014, p. 479) notes that "innovation comes from teams more often than from the light bulb moments of lone geniuses.”

The trend toward firms' use of within-firm collaborative approaches to invention has occurred in tandem with an increasing reliance on innovation as a source of firm-level competitive advantage, a theme highlighted across several streams of the strategy literature, including work on dynamic capabilities, high-velocity environments, and technology disruptions (e.g., Christensen, 1997; Teece, Pisano and Shuen, 1997; Pacheco-de-Almeida, 2010; D’Aveni, Dagnino and Smith, 2010; Bingham and Eisenhardt, 2011). Innovation output is particularly important to competitive advantage for newly-founded start-up firms, as it serves not only as an isolating mechanism in the product market, but also as a quality signal for external resource providers (Hsu and Ziedonis, 2013).

While recent work has linked firm-level competitive considerations with a firm's propensity to engage in team-based invention (Toh and Polidoro, 2013), there have been few 
studies to date examining the implications for firm-level innovation of alternate approaches to organizing these teams within a firm. This organization design decision regarding team composition represents an important managerial issue for high growth, knowledge-intensive firms. A main factor input for firm-level innovation is the firm's base of technical experience diversity as embodied in its set of inventors (Cohen and Levinthal, 1990; Grant, 1996; Coff, 1997; Katila and Ahuja, 2002). Conditional on the firm having such diversity, however, managers are likely to have discretion with respect to how this diversity is organized. This choice leads to the important organization design question which we address in this study: how do alternate approaches to organizing the diversity of technical experience contained in a firm's base of inventors influence innovation outcomes at the firm-level?

In Figure 1 we illustrate the distinction we make between these alternate firm-level approaches to organizing technical experience diversity. First, variation in diversity levels may exist within a team: inventors on a particular team may be more diverse or more uniform with respect to other inventors on that particular team. Second, such variation can be distributed across teams: the teams themselves can be conceptualized as being more diverse or more uniform as compared to the other teams. While studies on team design have examined diversity at the level of an individual team (e.g., Williams and O'Reilly, 1998), the within-firm, acrossteam perspective has seen little attention. Moreover, both dimensions of diversity have generally not been considered in light of the broader firm-level context and the associated design choices faced by managers. We believe that attending to this organization design perspective can offer an explanation for variation in firm-level innovation output. ${ }^{1}$

\footnotetext{
${ }^{1}$ We consider across-team diversity and within-team diversity to be theoretically independent constructs. While we illustrate the "joint" condition (high on one dimension, low on the other) in Figure 1 for ease of exposition, for the purpose of our theory development we are focused on their independent effects.
} 
[Insert Figure 1 here]

The roots of our theory development lie within the knowledge-based view (KBV) of the firm (Kogut and Zander, 1992; Grant, 1996). Central to the KBV is the notion that firms exist to "create the conditions under which multiple individuals can integrate their specialist knowledge" (Grant, 1996 p. 112), and moreover that "the central competitive dimension of what firms know how to do is to create and transfer knowledge efficiently within an organizational context" (Kogut and Zander, 1992 p. 384). The KBV's perspective of firms as "an institution for the organization of production" (Grant, 1996 p. 110, italics added) with individuals as the repositories of knowledge, links closely with our aim of understanding how differences in the organization of a firm's productive resources influences innovative performance in knowledgeintensive environments.

We aim to make three sets of contributions to the growing body of work in strategy linking organization design to innovation. First, while prior studies have examined the influence of internal firm organization on innovation (e.g., Argyres and Silverman, 2004; Ethiraj and Levinthal, 2004), the focus of this work has generally been at the level of the organizational subunit. Explicitly taking into account inventor-level characteristics - such as career experience in particular technology areas, as we do here — suggests a return to some of the fundamental principles of the KBV. Second, while the literature on organization design has collectively examined multiple levels of analysis (e.g., the individual, the unit, or the firm), few studies have spanned multiple such levels simultaneously. By focusing on the implications of diversity at multiple levels (within- and across-teams), we highlight possible tradeoffs in the function of organization design. Finally, whereas recent work in the domain of the KBV has advanced the notion of the "firm as a coordination system," (Srikanth and Puranam, 2014), emphasizing the 
unique advantages of coordinating activities within firm boundaries, we seek to re-inject the role of production into this discussion. By examining the interplay between production and coordination in the domain of knowledge generation, we hope to offer a complementary perspective that can build on and advance literature in this area.

Our theory development is anchored on a fundamental tension that we argue influences firm-level innovation output: the benefits of knowledge recombination arising from diverse sources of knowledge are traded off against the costs of coordination necessary to realize the benefits of this diversity. Recombination of prior knowledge is fundamental to the innovation process, and it reflects the need to gather diverse sets of information which can then be used in new ways (e.g., Weitzman, 1998; Fleming, 2001; Katila and Ahuja, 2002). In the inventor team context these processes entail the need for coordination as a consequence of reciprocal interdependencies among inventors (e.g., Thompson, 1967). Coordination costs thus interact with and shape the benefits of recombining a firm's productive knowledge. We examine how this plays out among the alternate models of across-team and within-team diversity.

Our main prediction is that firms with production teams organized using higher levels of across-team technical experience diversity will generate higher levels of innovative output at the firm-level as compared to those with higher levels of within-team diversity. To further test our theory, we examine two contingencies which we argue influence the knowledge recombinationcoordination costs tradeoff underlying this main prediction: the degree of prior "within-team joint collaborative experience" among the firm's inventors and the "combinatorial novelty" of the firm's inventions.

To empirically test our predictions we construct a panel dataset of 476 venture capitalbacked biotechnology firms that we observe from their date of founding onwards. We use 
biotechnology as our industry context as it is an environment where ongoing knowledge production is critical to competitive advantage and where team-based knowledge production is common. We use venture capital-backed firms in our sample in order to ensure homogeneity in firm quality; this setting further underscores the relevance of our patent-based measures of innovation, with patents serving both as a signal of quality, as well as a means of ensuring effective product market competition (Hsu and Ziedonis, 2013). We observe the full patenting history of each inventor in our firms (including not only their history in the focal firm, but their entire career history), allowing us to develop relevant measures of inventors' technology experience at any given point in time, as well as to facilitate inferences regarding team composition. Our results offer strong support for our predictions, with our insights moving us toward a deeper understanding of the link between organization design and innovation in knowledge-intensive environments.

\section{THEORY AND HYPOTHESES}

We begin our theory development by proposing a framing to analyze the effects of alternate firm-level design choices on innovation: the tradeoff between the benefits of knowledge recombination and the costs of coordination. We use this tension to develop our first hypothesis, which addresses the average relative impact on firm-level innovation of the two firm-level design choices (across-team and within-team technical experience diversity). Building on the mechanisms underlying our framework and the logic for our first hypothesis, we then develop two additional hypotheses that relate to the conditions under which each design choice may be beneficial with respect to its effect on firm-level innovation. 


\section{Theoretical framing: knowledge recombination and coordination costs}

An established stream of literature characterizes innovation as stemming from the recombination of existing ideas and knowledge (e.g., Schumpeter, 1934; Hargadon and Sutton, 1997; Fleming, 2001; Karim and Kaul, 2014). Recombination involves creating links across previously decoupled domains (Taylor and Greve, 2006; Yayavaram and Ahuja, 2008; Hsu and Lim, 2014), and is central to our understanding of firms' search processes, capabilities, and competitive advantage more generally (e.g., Nelson and Winter, 1982; Henderson and Clark, 1990; Katila and Ahuja, 2002; Carnabuci and Operti, 2013).

Innovation through recombination involves two separate conditions: the requisite knowledge must be present and accessible to the firm's inventors; and the firm must have the ability to use this knowledge in a way that generates novel and impactful inventions. Identifying and accessing knowledge for future inventions is driven by the firm's existing knowledge base (Cohen and Levinthal, 1990), the breadth of its available knowledge search space (Katila and Ahuja, 2002), and the degree to which knowledge can find its way from one part of the firm to another (Hansen, 2002). Prior studies have addressed the factors facilitating the degree and extent of knowledge sharing across different parts of a firm (Hansen, 2002). This work suggests that knowledge flows are more likely within (rather than across) firms (Singh, 2005) and that relatedness of knowledge, together with networks of inter-personal relations, can play an important role in influencing knowledge flow propensity (Hansen, 2002).

The ability to use available knowledge in novel ways is an equally important condition for impactful firm-level innovation, but it presents a particularly salient challenge for the types of within-firm team-based inventions we study: the need to coordinate across specialized but differentiated bodies of knowledge. Coordination needs arise when there are interdependencies 
among individuals in the production process (Thompson, 1967) and is amplified as the entities that need to coordinate become more specialized (Lawrence and Lorsch, 1967; Kretschmer and Puranam, 2008; Kotha, George and Srikanth, 2013). Coordination costs among inventors thus serve as a counter-balance to the benefits to innovation arising from knowledge recombination.

The tension between the benefits of knowledge recombination and the costs of coordination is one that is echoed in the literature on individual team dynamics, where diversity (defined broadly) has been examined in a range of contexts, including top management teams (Bantel and Jackson, 1989), product teams (Ancona and Caldwell, 1992), and work groups (Dahlin, Weingart and Hinds, 2005). This literature suggests that while increased diversity can have positive effects on various performance-linked outcomes at the team-level, it can also reduce the capability for teamwork (Ancona and Caldwell, 1992), lead to more formal and less frequent communications (Milliken and Martins, 1996), and introduce social barriers to utilizing information (Williams and O'Reilly, 1998). Thus, diverse teams face a tension between the learning benefits of different perspectives and the frictions which must be overcome for these benefits to be realized (Reagans and Zuckerman, 2001).

We seek to understand the implications of the knowledge recombination-coordination costs tradeoff from the perspective of a firm-level designer facing alternative design choices. In our conceptualization, teams are not atomistic, but rather reside within a firm context. In the next section we describe the two alternate firm-level design approaches to organizing diversity we consider, and then outline their expected implications for the firm-level knowledge recombination-coordination costs tradeoff. 


\section{Main effects of firm-level design choices on innovation}

Configuring technical experience diversity within the firm. Technical experience embodied in a firm's productive human capital (e.g., Grant, 1996; Coff, 1997) is an important factor influencing the firm's ability to innovate in technology-intensive environments. Any individual's technical experience includes that gained over her entire career, not just at the current firm. Such experience results in capability development over time (e.g., Dierickx and Cool, 1989), with the total stock of a firm's inventors' prior experiences influencing a firm's innovative capabilities and its future innovative success (Nelson and Winter, 1982; Henderson and Clark, 1990; Nerkar and Roberts, 2004). Breadth of experience is as important as depth in this regard (Katila and Ahuja, 2002; Leiponen and Helfat, 2010), as a broader range of prior technical experience among the firm's inventors increases the ability of the firm to recognize and assimilate new knowledge (Cohen and Levinthal, 1990).

It is likely that the specific way in which this diversity is configured will influence firmlevel innovation outcomes, as we would expect such design choices to impact the relative balance between knowledge recombination benefits and coordination costs. Technical experience diversity can be segmented into that which exists within teams and that which exists across teams (Figure 1). Greater within-team diversity involves a higher degree of diversity among inventors on a particular team; greater across-team diversity on the other hand represents a situation in which the teams themselves are different from one another. We discuss next the ways in which such design choices might influence knowledge recombination and coordination costs.

Impact of firm-level design choices on knowledge recombination. We first aim to assess the relative benefits of knowledge recombination as a function of whether diverse knowledge is located across- versus within- teams. To do so, we take the perspective of a given team and ask 
whether there are differences in the resulting knowledge creation if the underlying knowledge being recombined sits on the focal team or on a separate team (but still inside the firm). Note that separation in and of itself does not preclude teams within the same firm from sharing knowledge with one another (Hansen, 2002); such cross-team knowledge sharing in fact constitutes a primary reason for the firm's existence in the first place (Grant, 1996). ${ }^{2}$ Given the existence of such knowledge sharing, how and when does it matter where technical experience diversity resides?

In addressing this issue it is helpful to recognize that knowledge has different value depending on the specific context in which it is applied (Winter, 1987). The mere existence of knowledge with respect to a given technology is conceptually distinct from the ways in which this knowledge is ultimately utilized for productive purposes. From the perspective of a given team, the location of the underlying knowledge (inside versus outside the team) might influence the value that particular knowledge is able to bring to the team.

Prior literature suggests that recombining knowledge that spans organizational boundaries can yield innovation benefits (Rosenkopf and Nerkar, 2001; Nerkar and Roberts, 2004). Boundary spanning helps overcome the drawbacks stemming from core rigidities (Leonard-Barton, 1992) and competency traps (Levitt and March, 1988), and is consistent with recent findings showing that more disconnected actors lead to greater generative creativity (e.g., Fleming, Mingo and Chen, 2007). The core argument for the value of boundary spanning is that the capabilities arising from local search and routine development lead to an inward focus (e.g., on the part of a focal team) that negatively impacts innovation output (Stuart and Podolny, 1996; Sorenson and Stuart, 2000; Rosenkopf and Nerkar, 2001). By “acquiring and synthesizing

\footnotetext{
${ }^{2}$ There is, however, likely to be variation in the "barriers" around teams that may limit the degree of information sharing. This is an issue that is at the heart of the moderating hypothesis (H2) we develop in the next section.
} 
knowledge across boundaries," (Rosenkopf and Nerkar, 2001 p. 289), the impact of the resulting innovative combinations can be increased.

Although the literature on internal boundary spanning has generally focused on links across technology-related sub-units, it is likely that the analogous argument with respect to spanning intra-organizational team boundaries would also hold. Over time, a particular team is likely to develop joint routines and work processes among its inventors that reinforce the team's pre-disposition toward local search (e.g., Nelson and Winter, 1982; Levitt and March, 1988; Leonard-Barton, 1992). This bias leads to a convergence in perspectives, squandering many of the benefits of diversity with respect to how knowledge is used. These routines and work processes would impair the ability of the firm to develop its "combinative capabilities" (Kogut and Zander, 1992), negatively impacting the quality of its innovation output.

Locating the firm's diverse pieces of knowledge outside any given focal team would likely reduce the bias toward local search, as well as reduce the degree to which the focal team is constrained to a narrower conceptualization of the possible use of the knowledge in question. From the perspective of a firm-level organization designer, therefore, there are likely to be greater knowledge recombination benefits from organizing technical experience with acrossteam diversity rather than within-team diversity.

Impact of firm-level design choices on coordination costs. The need to coordinate arises from task modularization, whereby the firm allocates modules to teams (or to organizational subunits), and then integrates the resulting output from individual teams into a broader firm-level system (Lawrence and Lorsch, 1967; Kretschmer and Puranam, 2008). In the context of knowledge production, coordination costs thus likely arise both within and across individual 
teams. Our aim is thus to assess the relative costs of coordination in the across-team versus within-team diversity forms of organization.

It is in situations where reciprocal interdependencies are present that coordination costs are particularly high (Thompson, 1967). Ensuring the alignment of interdependent actions among individuals in such circumstances can involve frictions in communication and ongoing work interactions that ultimately reduce the effectiveness of joint output. These frictions arise because coordinating interdependent tasks involves the need for individuals to predict the actions of their interdependent counterparts, and to act accordingly (Puranam, Raveendran and Knudsen, 2012). The inability to do so can lead to coordination failures, introducing costs into the production process in which the interdependent individuals are engaged.

Assessing the relative costs of coordination in the across-team versus within-team diversity case thus involves identifying the level at which reciprocal interdependencies are more significant. While such interdependencies likely exist when "reintegrating" knowledge across teams, is it also likely that they will be greater in magnitude in the context of within-team interactions as compared to across-team interactions. Team-level production constitutes the lowest indivisible level of a firm's production output; as such, within-team interactions represent the root of the firm's creation and recombination activities. It is at the within-team level of the production process that individuals have the highest need to predict the actions of one another and to ensure alignment among interdependent actions. The existence of technical experience diversity within a team is likely to make it more difficult to employ mechanisms that mitigate coordination failures at this level, since diversity will reduce the level of common knowledge and shared understanding (Srikanth and Puranam, 2011) among inventors, leading to less efficient knowledge production outcomes. 
Summary and main prediction. Our discussion thus far suggests that on average acrossteam technical experience diversity is likely to have higher knowledge recombination benefits than within-team technical experience diversity as there is higher value to a focal team in utilizing knowledge that spans boundaries and is drawn from across separate teams. Across-team diversity will also result in lower coordination costs as compared to within-team diversity since coordination costs (stemming from reciprocal interdependencies) are most significant within a particular team's set of joint productive activities. Although within-team diversity may benefit from knowledge recombination, such benefits are likely to be lower on average than in the case of across-team diversity, with higher coordination costs at the same time. We thus predict that on average the net balance will be in favor of across-team diversity. ${ }^{3}$

Hypothesis 1: Firms organized with higher levels of across-team technical experience diversity will, on average, have higher firm-level innovation output as compared to those organized with higher levels of within-team technical experience diversity.

\section{Firm characteristics influencing the implications of the alternate design choices}

Our first hypothesis focuses on the average expected effect of across-team versus withinteam diversity with respect to firm-level innovation. There are likely to be conditions, however, that enhance the effects of one form of diversity versus the other. We thus turn to a set of possible moderating conditions for our first hypothesis, which also stem from the knowledge recombination-coordination costs framework introduced in the prior section. Empirical evidence for the effects of these moderators would offer further support for our main theoretical framework. We examine two moderators—-within-team joint collaborative experience and combinatorial novelty—and argue that the former decreases the firm-level innovation benefits of

\footnotetext{
${ }^{3}$ The degree to which one design choice promotes innovation relative to the other, however, is also likely to vary based on particular contextual factors, an issue we turn to in the next section as we discuss our two moderators.
} 
across-team diversity, while the latter increases the firm-level innovation benefits of within-team diversity.

Within-team prior collaborative experience refers to the extent to which inventors on a particular team have previously collaborated with one another in the context of prior inventions. Our logic for this moderator rests in part on its effect on knowledge recombination in the acrossteam diversity case. Recall that the across-team diversity effect is predicated on the existence of knowledge sharing across teams. As a result, the benefits from knowledge recombination in the case of across-team diversity stem from the ability of any given team to source knowledge from inventors on other teams. To the degree that there are conditions under which barriers to such knowledge sharing increase, the positive benefits from knowledge sharing would be reduced. We thus seek to understand whether there might be conditions under which across-team knowledge sharing is reduced.

Higher within-team prior collaborative experience is likely to increase such barriers. Experience of this type would likely increase the propensity of inventors on a particular team to be less receptive to knowledge from outside their own team. Our argument here relates in part to our prior discussion on boundary spanning. A key component of that argument was the propensity of a given team to evolve toward a set of within-team routines that shape the ongoing interactions among individuals on the team. With higher levels of within-team prior collaborative experience, there is likely to be greater collective identity and group cohesion, which in turn will increase the stability of within-team routines (Nelson and Winter, 1982; Levitt and March, 1988; Leonard-Barton, 1992). As these same sets of routines become increasingly well-established, the team becomes anchored to particular ways of operating, increasing the perceived costs of deviating from the collectively developed work processes and procedures of the team. It is likely 
in such a case that the team would be less proactive in seeking out new knowledge, thereby reducing the possibility of enjoying knowledge recombination benefits as a consequence of the across-team design form.

In addition to the reduction in across-team knowledge sharing, there is likely to be a secondary effect arising from the contingency of within-team joint collaborative experience that further attenuates the benefits to innovation of across-team diversity. Recall that the discussion regarding the relative costs of coordination under across-team versus within-team diversity suggested that the need to coordinate in the context of across-team "reintegration" was less costly than the need to coordinate in the context of within-team production. As teams increasingly evolve into their own silos, the associated specialization will likely increase the costs of across-team reintegration (Kretschmer and Puranam, 2008). The associated increase in coordination costs would further attenuate the beneficial effects of across-team diversity. The collective arguments regarding within-team joint collaborative experience as a contingent effect on across-team technical experience diversity suggest the following hypothesis:

\section{Hypothesis 2: Within-team joint collaborative experience will negatively moderate the} effect of across-team technical experience diversity on innovation.

Finally, we turn to a possible contingency for the within-team diversity effect on innovation. We focus on what we call "combinatorial novelty." This refers to the degree to which the firm's inventions involve recombining technology areas that are relatively infrequently combined in the broader market. We argue that this construct will positively moderate the effect of within-team diversity on innovation. There are two components to our argument for combinatorial novelty as a contingency. The first concerns the benefits stemming from diversity. As the innovations sought by the firm become increasingly complex and novel, teams benefit 
from keeping the necessary production process knowledge within the team itself. Doing so reduces search costs and frictions associated with seeking out knowledge from other teams. The second part of the argument concerns the associated coordination costs. Recall that a key driver of the reduced innovation output of within-team diversity (relative to across-team diversity) is the increase in coordination costs stemming from the diversity of individual backgrounds that must work together in pursuit of a common output, with higher within-team diversity involving greater coordination costs as compared to higher across-team diversity. To the degree that there are conditions leading to the gap in coordination costs between these two forms of organization to narrow, the innovation deficit in the within-team diversity case relative to the across-team diversity case would shrink.

Greater combinatorial novelty involves higher levels of knowledge complexity, making it more difficult for the firm to manage the interdependencies in recombined knowledge across the firm (Fleming and Sorenson, 2001). It is therefore likely that coordination costs associated with across-team diversity would increase under greater combinatorial novelty. While within-team coordination costs may also increase in such a setting, we are concerned specifically with the relative increase in coordination costs under one form of diversity versus the other. Since combinatorial novelty concerns integration issues at the level of the firm itself, the increase in coordination costs in such a situation will likely affect across-team diversity more so than withinteam diversity. This would reduce the gap between the coordination costs associated with the two types of diversity, thereby reducing the innovation penalty associated with within-team diversity. Putting these arguments together, our final prediction then is that combinatorial novelty will positively moderate the effect of within-team diversity on innovation. 
Hypothesis 3: Combinatorial novelty of a firm's inventions will positively moderate the effect of within-team technical experience diversity on innovation.

\section{METHODS AND RESULTS}

\section{Data and sample}

We sample the universe of 476 venture capital-backed human biotechnology (SIC codes 2833-2836) firms founded between 1980 and 2000, as identified by the VentureXpert database. This industry setting has several favorable characteristics for the purpose of this study. First, entrepreneurial firms in an R\&D-intensive environment provide a setting in which knowledgebased resources are an important driver of competitive advantage, consistent with our objective of understanding knowledge-based human capital. Smaller firms with one or few locations also represent a context with managerial flexibility with respect to team design and one in which knowledge sharing across teams may be more feasible (as compared to a multiproduct, multinational setting). Second, since patenting is key to value appropriation in the biotechnology industry (e.g., Levin et al., 1987), we can be more confident that our reliance on patent data to measure individual- and team-level characteristics within firms as well as innovation outcomes reflects team composition structures. While patent data may give rise to issues of generalizability (as we discuss in our final section), it has the benefit of allowing us to observe staffing decisions in a large sample panel set-up, a task that would otherwise be quite difficult. Finally, we desire as homogeneous a sample as possible, apart from the dimension of team organization, so that we can construct comparable and meaningful measures of innovation. Confining our sample to a single industry setting provides some uniformity in interpreting firm-level objectives; moreover, restricting the sample to venture capital-backed firms further increases the commonality of the 
likely objectives and time horizon issues facing our sample of firms (thereby reducing the potential for unobserved differences across firms).

Our primary dataset is an unbalanced firm-year panel in which firms are observed from their year of founding through either 2009 or their year of dissolution. In order to facilitate within-firm inferences (as discussed later, in part through employing specifications with firm fixed effects) a longer time window of observation is desirable. In addition to including all years in which the firm is privately held, we also include in our observation window years post-IPO and post-acquisition of the focal firm by another entity (together with controls for these alternate ownership regimes). ${ }^{4}$ We utilize several sources to construct our variables. The IQSS Patent Network database (Li et al., 2014) includes all U.S. Patent and Trademark Office data on patents applied for since 1975 and allows us to uniquely identify inventors associated with patents and construct various team measures. Firm-year level attributes come from Deloitte Recap RDNA, Pharmaprojects, Inteleos, ThomsonOne, Zephyr, and various SEC filings.

\section{Variable definitions}

Firm-level innovation output. Our main dependent variable is the number of forward citations received within a 4-year post-application window to the firm's patents in the focal firmyear. Forward citations are an accepted measure both of economic value (Trajtenberg, 1990) and innovative impact (Jaffe and Trajtenberg, 2002). Maintaining a fixed citation window allows us to make meaningful comparisons across observation years; without such a window older patents would be artificially biased upwards in citation count. Our main independent variables of theoretical interest are across-team and within-team technical experience diversity, together with

\footnotetext{
${ }^{4}$ In order to collect patent data on a firm's post-M\&A years we follow the procedure outlined in Aggarwal and Hsu (2014), which relies on identifying a firm's pre-acquisition inventors, and matching these to patenting activity by the same inventors in the acquiring firm post-acquisition.
} 
our two moderators. In the following variable descriptions we use a subscript notation convention as follows: firm $f$, time $t$, dyad $d$, inventor $i$, patent $p$, patent class $c$, and patent subclass $s$.

Across-team and within-team diversity. Within-team diversity is designed to measure dyadic diversity (in technical experience) among different inventors on a given patent team. We measure the angular distance between the functional experience of every pair of inventors on a team (as described in more detail below), and then average over all pairs of inventors on a team. To aggregate this measure to the firm-level we then average over all teams in a firm-year (our unit of analysis). Across-team diversity is designed to measure how patent teams differ from one another (in terms of technical experience) on a pairwise (dyadic) basis. To construct this variable we first measure the distance between the functional experience of every pair of patent teams, and then average over all such pairs. ${ }^{5}$

We measure the diversity between any pair of inventors $i$ and $-i$ using a cosine similarity measure, also known as angular distance, or angular separation (Jaffe, 1986). For a given inventor $i$ at time $t$, we define the vector ClassExp $i t$ as the total experience the inventor has had throughout her career, both in her current firm and in all prior firms, patenting across different technological classes. The vector is of dimension $C \times 1$, where $C$ is the total number of primary patent classes. Each entry of the vector represents a stock count of the inventor's patents in that particular technological class. Cosine similarity is defined as the angular separation between the class experience vectors of the two inventors (per Jaffe, 1986), while diversity is defined as 1

\footnotetext{
${ }^{5}$ We organize our empirical analyses with these two forms of diversity treated as independent constructs. In unreported results we find that our theoretical predictions are robust to the inclusion of the interaction effect among the two constructs. We also find that the interaction is not significant in our model specifications; we thus choose to report the more concise model specification (i.e., without the interaction), as this specification in any case concords more closely to our theoretical framework.
} 
minus the cosine similarity of the two inventors. The diversity measure thus ranges from 0 to 1 , where 1 is completely diverse (no technological overlap) and 0 is completely homogeneous (full technological overlap).

To construct the within-team diversity measure, for a given team of inventors $i \in I_{p}$ on a patent $p$ — referred to as a patent team—we form all possible dyads $d_{i,-i} \in D_{p}^{i n v}$ between the team of inventors; the superscript indicates that the dyads are between inventors, and the subscript indicates that there is a set of dyads for each patent. For each patent, we average over the set of all inventor dyads, forming a diversity measure for each patent. We then average over all patents in a firm-year, $p \in P_{f t}$. To construct the across-team diversity measure, we sum the class experience vectors of the inventors $i$ at time $t$ on a patent team (i.e., the set of inventors on a given patent) and create a single class experience vector for the entire patent team, PatTeamExp $p_{p}$ We then take the set of patents $p \in P_{f t}$ and form all possible dyads $d_{p,-p} \in$ $D_{f t}^{p a t}$. For each dyad, we calculate the diversity measure as before, but instead using PatTeamExp in place of ClassExp $p_{i t}$, with the final measure then constructed as an average over all dyads of patent teams.

Prior collaborative experience. We construct measures of prior collaborative experience between different inventors. For any two inventors $i$ and $-i$, joint experience at time $t$ is defined as the stock count of patents for which both inventors were on the same patent team at any point in their career through time $t$. Our main focus is on within-team collaborative experience, one of our two moderators. We also calculate total collaborative experience as a control. Within-team collaborative experience is constructed by first calculating the joint experience between all dyads of inventors on the same patent team, averaged over the number of possible dyads within a patent team. The measure is then averaged over all patent teams in a firm-year. Total 
collaborative experience is the average level of joint experience among all dyads formed from the full set of inventors patenting in firm $f$ at time $t$-i.e., all inventors in a firm-year.

Combinatorial novelty. Our measure of combinatorial novelty draws on the measure of complexity in Fleming (2001) and Fleming and Sorenson (2001). Their measure proposes that truly novel inventions recombine technological components that have not been frequently recombined in the past. Patent subclasses represent the technological components. Ease of recombination $E_{s t}$ of subclass $s$ at time $t$ is defined as the ratio of the number of subclasses combined with $s$ and the number of previous patents in $s$ (put another way, this refers to how often new components are combined with a focal component, normalized by the number of times the focal component appears). The combinatorial novelty $C_{p}$ of patent $p$ simplifies to the sum over all the ease of recombination measures $E_{s t}$ for all subclasses on the patent at the time of the patent application: $C_{p}=\sum_{s \in S_{p}} E_{s t}$. This measure thus gets larger when there are more subclasses combined with each of the subclasses on the focal patent and when there are more subclasses on the focal patent, but gets smaller when there are more previous patents in the subclasses on the focal patent. $C_{p}$ is aggregated to our firm-year measure of combinatorial novelty by averaging over all patents $P_{f t}$ in a firm-year patent portfolio.

Controls. Our main theoretical focus is on the alternate models of inventor team organization (across- and within-team diversity), together with the two moderators of withinteam collaborative experience and combinatorial novelty. Accordingly, we seek to employ a set of time-varying controls, each measured at the firm-year level, in order to account for any residual unobserved heterogeneity beyond the time invariant firm-level characteristics we control for with firm fixed effects (which are included in all of our specifications). There are three 
categories of controls: inventor team controls; firm patenting controls; and corporate (firm-level) controls. We discuss the rationale for each category of controls in turn.

The "inventor team controls" account for the technological experience embodied in the firm's inventors, measured as an aggregate total at the individual team level, and then averaged across teams in the firm-year. Inventor experience includes not only that gained by inventors within the context of the firm itself, but also that which the firms' inventors have gained over the course of their entire careers. We include the following variables: team patenting experience, which measures the collective number of patents held by inventors on the firm's patent teams; team forward citation experience, which similarly measures the collective number of forward citations of the inventors on a team; and team class experience, which measures the unique number of patent classes represented by inventors on a team. All measures are averaged across the firm's patent teams in a given firm-year. Employing this set of controls thus broadly accounts for the overall experience level of the firm's inventors. As discussed later, we further use these controls as part of a set of robustness checks we run using coarsened exact matching (CEM). The "firm patenting controls" measure characteristics of the firm's overall portfolio of inventors and experience. In conjunction with the slate of "corporate controls" described next, this set of variables accounts for various time-varying dimensions of firm scale, scope, and quality, all of which may be correlated with both team design characteristics and innovation output. The firm patenting controls include patent count, which is the total number of patents applied for by the firm in the firm-year; inventor count, which is the unique number of inventors in the firm-year; and class span, which is the unique number of classes in which the firm patents in the firm-year. This set also includes the measure of total collaborative experience described 
earlier, which accounts for the overall level of joint experience between the firm's inventors (the average of their joint dyadic experience), disregarding team boundaries.

Finally, the "corporate controls" further account for a set of time-varying characteristics that could correlate with team design and innovation. Collectively these variables measure various characteristics of firm quality and development stage that are relevant in our industry setting of early-stage venture capital-backed biotechnology firms. These controls include the age of the firm; VC inflows stock, which measures cumulative venture capital investment into the firm (from VentureXpert); strategic alliance stock, which measures the cumulative stock of the alliances in which the firm has been involved to date (from Deloitte Recap RDNA); and active product (all stages), which is an indicator for whether the firm has at least one active product in the Food and Drug Administration (FDA) pipeline (from PharmaProjects and Inteleos). We also control for the firm's ownership using the post-IPO and post-M\&A variables (privately-held is the baseline), as the ownership regime of the firm is likely to influence both team organization and innovation (these variables are hand-collected using archival news sources). Post-IPO indicates that the firm has undergone an initial public offering (IPO) at some point in its history; and post-M\&A is an indicator that the firm has been acquired. Table 1 provides definitions and summary statistics, while Table 2 provides pair-wise correlations of our independent variables.

[Insert Tables 1 and 2 here]

\section{Model specifications}

We employ conditional fixed effects Poisson models with robust standard errors in our main analyses. This estimation technique is appropriate because our dependent variable, forward citations (4Y), is a non-negative count (Hausman, Hall and Griliches, 1984; Hall and Ziedonis, 2001). We employ firm and year fixed effects throughout in order to control for time-invariant 
firm qualities and year-to-year changes that might correlate with both production team organization and firm innovation. Together with the set of controls described above, the conditional firm fixed effects specification facilitates the interpretation of our results as estimating within firm, across time effects. While this estimation approach allows us to mitigate many of the concerns related to the possibly endogenous assignment of team structures, we also employ a coarsened exact matching (CEM) approach as a robustness check in order to provide further evidence that our results may not be driven purely by selection of firms into particular patterns of team design.

The goal of CEM is to pre-process data in order to reduce imbalance between "treatment" and "control" groups (Blackwell et al., 2009; Iacus, King and Porro, 2011; Iacus, King and Porro, 2012). Matching on a set of observable measures to better align the distributional characteristics of these groups helps reduce concerns of statistical bias and model dependence (Iacus et al., 2011), with these concerns stemming from the possibility that the treatment and control groups may be systematically driven by different data generation processes. In our setting, for example, it may be the case that characteristics of the firms' inventors' prior experience can drive selection into one form of team organization versus another.

CEM has beneficial statistical properties as compared to other matching methods (Iacus et al., 2011), with the treatment-control balance determined ex ante: observed covariates are "coarsened" into bins; coarsened data are "pruned" and matched into strata, creating weights for each observation so that strata have at least one treatment and one control unit; and estimates are then run on the original un-coarsened data with the CEM weights. ${ }^{6}$ As discussed in the Results section, we match on the set of inventor team controls, and then utilize two alternate approaches

\footnotetext{
${ }^{6}$ Recent studies employing this technique include Azoulay, Graff Zivin and Wang (2010), and Singh and Agarwal (2011). We follow the methodological approach outlined in Blackwell et al. (2009).
} 
to defining treatment and control groups, using above- and below-median levels of across- and within-team diversity. Since a conditional fixed effects Poisson model cannot incorporate CEM weights, we use fixed effects OLS estimates with the natural log of $(1+$ forward citations $)$ as our dependent variable on the post-CEM processed data.

\section{Empirical results}

Table 3 reports the specifications we use to test our main effects. The reported coefficients are incidence rate ratios - i.e., the exponentiated Poisson regression coefficients. The interpretation of these coefficients is as follows: for a one unit increase in an independent variable, the incidence rate of the dependent variable would be expected to be scaled (multiplied) by the value of the coefficient on that independent variable. Thus, a coefficient value less than one should be interpreted as a negative effect, while a coefficient value greater than one should be interpreted as a positive effect.

Technical experience diversity. In Table 3 we report the results of the across-team and within-team diversity effects. Specification (3-1) reports just the across-team and within-team results, while (3-2) adds team controls, and (3-3) includes the remainder of our firm-level controls. ${ }^{7}$ We use Poisson specifications with both firm and year fixed effects (and robust standard errors) in all models, and run the analyses at the firm-year level. We see that there is a positive effect on across-team diversity and a negative effect on within-team diversity (recall that the coefficients are incidence rate ratios), results which are consistent across the three specifications. The results suggest that shifting the across-team structure of a firm from complete functional experience homogeneity (0) to fully diverse (1) yields $103.3 \%$ more forward citations in the most parsimonious specification (3-1) to $58.3 \%$ more forward citations in the full

\footnotetext{
${ }^{7}$ We also find (in unreported regressions) that our results are robust to including various combinations of the firm patenting controls of patent count, inventor count, and class span.
} 
specification (3-3). Going from complete within-team functional homogeneity (0) to full withinteam diversity (1) results in approximately $50 \%$ fewer forward citations in these specifications. We perform a Wald test on the equality of the coefficients for across-team and within-team diversity in each of the three specifications and can reject the null that the coefficients are equal with $0.1 \%$ significance. These specifications thus show strong evidence of our hypothesis (H1) that across-team diversity is positively related to innovation relative to within-team diversity.

\section{[Insert Table 3 here]}

Moderating effects. In Table 4, we introduce our two moderators: within-team collaborative experience and combinatorial novelty. Our results on across-team and within-team diversity have the same sign and approximate magnitude throughout the specifications, with both sets of effects consistently significant at either the $1 \%$ or $5 \%$ levels. In models (4-1) and (4-2) we test the within-team collaborative experience moderator $(\mathrm{H} 2)$, with the interaction terms excluded in (4-1) and included in (4-2); we follow a parallel approach for the combinatorial novelty moderator (H3) in models (4-3) and (4-4). In model (4-2) we find that high within-team collaborative experience moderates the positive effect of across-team diversity, but not to the point of completely offsetting the main diversity effect. In model (4-4) we find that high combinatorial novelty reverses the negative effect of within-team diversity. These two sets of specifications are therefore consistent with $\mathrm{H} 2$ and $\mathrm{H} 3$. Our direct and interaction effects hold (and are strengthened in significance) in the full model (4-5).

[Insert Table 4 here]

In Figure 2 we present graphical representations of our interaction effects, showing the effect of across- and within-team diversity in low and high cases of the moderators. For each figure, we evaluate the predicted values of forward citations for values of across-team diversity 
and within-team diversity at the fifth- and ninety-fifth percentile of the distribution of values (referred to as low and high respectively) of within-team collaborative experience and combinatorial novelty. The y-axis represents predicted forward citations from our model, with a positive (negative) slope indicating a positive (negative) association between the diversity measure and the dependent variable.

[Insert Figure 2 here]

CEM. Finally, in Tables 5A and 5B we conduct robustness checks of our results using the CEM procedure to pre-process our data. Robust results with this procedure would provide further evidence supporting the claim that our empirical results are not entirely driven by selfselection into particular team organizational forms. We utilize alternate definitions of the "treatment," balancing separately on above versus below-median across-team diversity and above versus below-median within-team diversity. We match on the set of control variables related to inventor experience. These variables proxy for the total experience available for the firm to organize into different team structures, and thus represent important observable characteristics that might drive endogenous selection into particular team design structures.

Table 5A shows that the CEM procedure helps balance the control variables between high and low levels of across- and within-team diversity. The "pre" and "post" columns indicate the difference in means of the selected variables before and after the CEM balancing process, again separately using the across-team diversity and within-team diversity (above versus below median) treatments. As Table 5A shows, after the balancing process there are no statistically significant differences in the means of the matching variables. In Table 5B, we then run fixed effects OLS models with robust standard errors on the balanced samples (note that in contrast with the incidence rate ratios we report in Table 4, the values reported in Table 5B should be 
interpreted as the usual positive and negative OLS coefficients). We find evidence for all of our hypotheses, with statistically significant coefficients (and the theoretically predicted signs) on across-team diversity, within-team diversity, and the interactions of these variables with withinteam collaborative experience and combinatorial novelty.

[Insert Tables 5A and 5B here]

\section{DISCUSSION AND CONCLUSION}

This study examines the link between the organization of a firm's production-oriented human capital and firm-level innovation. The trend toward collaborative, team-based approaches to innovation in recent decades has been coupled with an increasing reliance on innovation as a centrally important source of firm-level competitive advantage. We address the role of technical experience diversity inside the firm in this regard, focusing specifically on the differing effects of across-team and within-team diversity. We construct a panel dataset of 476 venture capitalbacked biotechnology firms that we observe from their year of founding onwards. The results are consistent with our theoretical framework in which production team design choices where firmlevel innovation is the outcome of interest involves balancing knowledge recombination benefits against coordination costs. We find that across-team diversity has a greater impact on firm-level innovative output than within-team diversity, with the across-team and within-team effects moderated respectively by the firm's within-team collaborative experience and its overall combinatorial novelty.

Our results allow us to develop a deeper understanding of the link between organization design and innovation. Few studies to date have examined the ways in which alternate structures of organizing inventor teams might influence firm-level innovation output. This is an important and fundamental managerial question, however, given the increasing importance of innovation as 
a source of firm-level competitive advantage, and the increasing relevance of teams in the innovation process. We add several dimensions to the literature in this area. While much of the more recent work on organization design has examined organizational sub-units, we suggest a return to the original spirit of the $\mathrm{KBV}$ with a focus on mechanisms that derive from the experience of individuals. Our study also highlights the importance of looking across levels of analysis in considering organization design issues by focusing on both the within- and acrossteam levels. Finally, we advance work at the intersection of the KBV and organization design literatures by considering the interplay between production and coordination. Together, these results offer an important perspective on the role that organizational issues can play in helping firms translate their production-oriented human capital into innovative outputs.

Our study has several limitations, which should be considered in interpreting the results. A first set of issues relates to our use of patent data in order to identify team structures. While a benefit of our approach is that we are able to infer possible staffing allocations in a large sample setting, we do not observe such staffing decisions directly. However, a patent represents a tangible piece of real productive output, lending credence to the premise that co-inventors on a particular patent did indeed work together as a team toward a common goal. It should also be noted that we only observe patents that are ultimately awarded to firms (though research suggests that about $85 \%$ of patent applications are granted (Lemley and Sampat, 2008)). While this may introduce the bias of not being able to observe the outcomes of unsuccessful team efforts, this is a commonly known limitation of patent-based work. Using forward citations as our dependent variable helps mitigate this concern, as it allows us to observe variation in the degree of success associated with a particular level of team output. Nevertheless, our outcome measure should be interpreted as censoring output below a base level of team success. 
A second set of limitations involves our focus on a single industry. Generalizing to settings beyond biotechnology may thus entail utilizing output measures of innovation beyond patents. While our empirical tests are anchored in the patent-based context, our theory is constructed to be agnostic to the particular setting. Along the dimension of firm development stage, we utilize an entrepreneurial setting because it both mitigates the problem of left-censoring (since we observe firms from their date of founding onwards), and also because knowledgebased considerations are more relevant in such settings. Further work could examine how our theory fares in the context of large, multi-location firms (e.g., diversified pharmaceutical firms) where knowledge mobility may be more restricted, and structural and incentive considerations may interact in interesting ways with our core theoretical tension of knowledge recombination and coordination costs.

A final set of limitations involves the degree to which we can make causal claims given our empirical set-up, as team structure decisions within firms may not be randomly assigned. Our use of firm fixed effects, a broad set of time-varying control at multiple levels, together with robustness checks using a matching methodology with alternative approaches to constructing the treatment sample suggests that our key findings are robust, and moreover that they are likely to be driven by factors beyond mere selection by firms of teams into particular organizational structures. This last point regarding endogenous team formation presumes managerial knowledge regarding optimal organization, a condition we doubt holds. Nevertheless, we remain cautious in interpreting causal relations in the absence of an instrument for organizational form or a natural experiment.

These various limitations notwithstanding, we believe that our results, particularly on the across-team diversity dimension, contribute to the literature and can open new avenues for future 
research. One such direction relates to our understanding of the role of individuals in the context of firm-level strategy. While a host of theories in the strategy field, including the KBV, have originally sought to place individuals in a central theoretical role, the degree to which empirical work has taken into account individual-level factors has often been limited. It is partly for this reason that there is increasing recognition of the value in moving toward a deeper understanding of the "microfoundations" of strategy. Our theory and results thus offer a step in the direction of developing a deeper understanding of such issues for future research, particularly in the domain of knowledge production and innovation.

Our results also suggest that future work on organization design—particularly work on teams and other intermediate levels of analysis between individuals and the firm (such as production units more generally) — can benefit from taking into account the "across-unit" dimension of organization. While the within-team dimension of diversity has been well-studied, the across-team dimension has been relatively understudied. Paying closer attention to the role of across-team organization may lead to a potentially fruitful interplay between the rich literatures on teams and on organization design.

Finally, understanding the micro-processes that facilitate knowledge recombination and mitigate coordination costs, linking these mechanisms of knowledge creation to the related processes of creativity and decision making, and understanding the implications of these design considerations in the context of rapidly changing and discontinuous environments represent just a sampling of potential future avenues for research in this domain. Our results help lay the groundwork for these types of future studies by deepening our understanding of the link between organization design and innovation, and in particular the ways in which alternate structures of organizing inventor teams relate to firm-level innovation output. 


\section{REFERENCES}

Aggarwal VA, Hsu DH. 2014. Entrepreneurial exits and innovation. Management Science 60 (4): 867-887.

Ancona DG, Caldwell DF. 1992. Demography and design: predictors of new product team performance. Organization Science 3 (3, Focused Issue: Management of Technology): 321341.

Argyres NS, Silverman BS. 2004. R\&D, organization structure, and the development of corporate technological knowledge. Strategic Management Journal 25 (8-9): 929-958.

Azoulay P, Graff Zivin JS, Wang J. 2010. Superstar extinction. Quarterly Journal of Economics 125 (2): 549-589.

Bantel KA, Jackson SE. 1989. Top management and innovations in banking: does the composition of the top team make a difference? Strategic Management Journal 10 (S1): 107124.

Barney J. 1991. Firm resources and sustained competitive advantage. Journal of Management 17 (1): 99-120.

Bingham CB, Eisenhardt KM. 2011. Rational heuristics: the 'simple rules' that strategists learn from process experience. Strategic Management Journal 32 (13): 1437-1464.

Blackwell M, Iacus SM, King G, Porro G. 2009. CEM: coarsened exact matching in Stata. Stata Journal 9 (4): 524-546.

Boudreau K. 2010. Open platform strategies and innovation: granting access vs. devolving control. Management Science 56 (10): 1849-1872.

Carnabuci G, Operti E. 2013. Where do firms' recombinant capabilities come from? intraorganizational networks, knowledge, and firms' ability to innovate through technological recombination. Strategic Management Journal 34 (13): 1591-1613.

Christensen C. 1997. The Innovator's Dilemma: When New Technologies Cause Great Firms to Fail. Harvard Business Review Press: Cambridge, MA.

Coff RW. 1997. Human assets and management dilemmas: coping with hazards on the road to resource-based theory. Academy of Management Review 22 (2): 374-402.

Cohen WM, Levinthal DA. 1990. Absorptive capacity: a new perspective on learning and innovation. Administrative Science Quarterly 35 (1, Special Issue: Technology, Organizations, and Innovation): 128-152.

Cyert RM, March JG. 1963. A Behavioral Theory of the Firm. Englewood Cliffs, NJ.

Dahlin KB, Weingart LR, Hinds PJ. 2005. Team diversity and information use. Academy of Management Journal 48 (6): 1107-1123.

D'Aveni RA, Dagnino GB, Smith KG. 2010. The age of temporary advantage. Strategic Management Journal 31 (13): 1371-1385.

Dierickx I, Cool K. 1989. Asset stock accumulation and sustainability of competitive advantage. Management Science 35 (12): 1504-1511.

Ethiraj SK, Levinthal D. 2004. Modularity and innovation in complex systems. Management Science 50 (2): 159-173.

Fleming L. 2001. Recombinant uncertainty in technological search. Management Science 47 (1, Design and Development): 117-132.

Fleming L, Mingo S, Chen D. 2007. Collaborative brokerage, generative creativity, and creative success. Administrative Science Quarterly 52 (3): 443-475. 
Fleming L, Sorenson O. 2004. Science as a map in technological search. Strategic Management Journal 25 (8-9): 909-928.

Fleming L, Sorenson O. 2001. Technology as a complex adaptive system: evidence from patent data. Research Policy 30 (7): 1019-1039.

Grant RM. 1996. Toward a knowledge-based theory of the firm. Strategic Management Journal 17 (S2): 109-122.

Gulati R, Puranam P, Tushman M. 2012. Meta-organization design: rethinking design in interorganizational and community contexts. Strategic Management Journal 33 (6): 571-586.

Hall BH, Ziedonis RH. 2001. The patent paradox revisited: an empirical study of patenting in the U.S. semiconductor industry, 1979-1995. RAND Journal of Economics 32 (1): 101-128.

Hansen MT. 2002. Knowledge networks: explaining effective knowledge sharing in multiunit companies. Organization Science 13 (3): 232-248.

Hargadon A, Sutton RI. 1997. Technology brokering and innovation in a product development firm. Administrative Science Quarterly 42 (4): 716-749.

Hausman J, Hall BH, Griliches Z. 1984. Econometric models for count data with an application to the patents-r\&d relationship. Econometrica 52 (4): 909-938.

Henderson RM, Clark KB. 1990. Architectural innovation: the reconfiguration of existing product technologies and the failure of established firms. Administrative Science Quarterly 35 (1, Special Issue: Technology, Organizations, and Innovation): 9-30.

Hilbe JM. 2011. Negative Binomial Regression. Cambridge University Press: Cambridge, UK.

Hsu DH, Lim K. 2014. Knowledge brokering and organizational innovation: founder imprinting effects. Organization Science 25 (4): 1134-1153.

Hsu DH, Ziedonis RH. 2013. Resources as dual sources of advantage: implications for valuing entrepreneurial-firm patents. Strategic Management Journal 34 (7): 761-781.

Iacus SM, King G, Porro G. 2012. Causal inference without balance checking: coarsened exact matching. Political Analysis 20 (1): 1-24.

Iacus SM, King G, Porro G. 2011. Multivariate matching methods that are monotonic imbalance bounding. Journal of the American Statistical Association 106 (493): 345-361.

Isaacson W. 2014. The Innovators: How a Group of Inventors, Hackers, Geniuses, and Geeks Created the Digital Revolution. Simon and Schuster: New York, NY.

Jaffe AB, Trajtenberg M. 2002. Patents, Citations, and Innovations: A Window on the Knowledge Economy. MIT Press: Cambridge, MA.

Jaffe AB. 1986. Technological opportunity and spillovers of r\&d: evidence from firms' patents, profits, and market value. American Economic Review 76 (5): 984-1001.

Jones BF. 2009. The burden of knowledge and the "death of the renaissance man": is innovation getting harder? Review of Economic Studies 76 (1): 283-317.

Karim S, Kaul A. 2014. Structural recombination and innovation: unlocking intraorganizational knowledge synergy through structural change. Organization Science, forthcoming.

Katila R, Ahuja G. 2002. Something old, something new: a longitudinal study of search behavior and new product introduction. Academy of Management Journal 45 (6): 1183-1194.

Kleinbaum AM, Stuart TE, Tushman ML. 2013. Discretion within constraint: homophily and structure in a formal organization. Organization Science 24 (5): 1316-1336.

Kogut B, Zander U. 1992. Knowledge of the firm, combinative capabilities, and the replication of technology. Organization Science 3 (3, Focused Issue: Management of Technology): 383397. 
Kortum S, Lerner J. 2000. Assessing the contribution of venture capital to innovation. RAND Journal of Economics 31 (4): 674-692.

Kotha R, George G, Srikanth K. 2013. Bridging the mutual knowledge gap: coordination and the commercialization of university science. Academy of Management Journal 56 (2): 498-524.

Kretschmer T, Puranam P. 2008. Integration through incentives within differentiated organizations. Organization Science 19 (6): 860-875.

Lawrence PR, Lorsch JW. 1967. Differentiation and integration in complex organizations. Administrative Science Quarterly 12 (1): 1-47.

Leiponen A, Helfat CE. 2010. Innovation objectives, knowledge sources, and the benefits of breadth. Strategic Management Journal 31 (2): 224-236.

Lemley MA, Sampat B. 2008. Is the patent office a rubber stamp. Emory LJ 58 : 181.

Leonard-Barton D. 1992. Core capabilities and core rigidities: A paradox in managing new product development. Strategic Management Journal 13 (S1): 111-125.

Levin RC, Klevorick AK, Nelson RR, Winter SG, Gilbert R, Griliches Z. 1987. Appropriating the returns from industrial research and development. Brookings Papers on Economic Activity 1987 (3, Special Issue On Microeconomics): 783-831.

Levitt B, March JG. 1988. Organizational learning. Annual Review of Sociology 14 : 319-340.

Li G, Lai R, D’Amour A, Doolin DM, Sun Y, Torvik VI, Yu AZ, Fleming L. 2014. Disambiguation and co-authorship networks of the U.S. patent inventor database (19752010). Research Policy 43 (6): 941-955.

Milliken FJ, Martins LL. 1996. Searching for common threads: understanding the multiple effects of diversity in organizational groups. Academy of Management Review 21 (2): 402433.

Nelson RR, Winter SG. 1982. An Evolutionary Theory of Economic Change. Belknap Press: Cambridge, MA.

Nerkar A, Roberts PW. 2004. Technological and product-market experience and the success of new product introductions in the pharmaceutical industry. Strategic Management Journal 25 (8-9): 779-799.

Pacheco-de-Almeida G. 2010. Erosion, time compression, and self-displacement of leaders in hypercompetitive environments. Strategic Management Journal 31 (13): 1498-1526.

Penrose ET. 1959. The Theory of the Growth of the Firm. Oxford University Press: Oxford, United Kingdom.

Peteraf MA. 1993. The cornerstones of competitive advantage: a resource-based view. Strategic Management Journal 14 (3): 179-191.

Puranam P, Raveendran M, Knudsen T. 2012. Organization design: the epistemic interdependence perspective. Academy of Management Review 37 (3): 419-440.

Reagans R, Zuckerman EW. 2001. Networks, diversity, and productivity: the social capital of corporate r\&d teams. Organization Science 12 (4): 502-517.

Rosenkopf L, Nerkar A. 2001. Beyond local search: boundary-spanning, exploration, and impact in the optical disk industry. Strategic Management Journal 22 (4): 287-306.

Rubin DB. 1976. Inference and missing data. Biometrika 63 (3): 581-592.

Schumpeter JA. 1934. The Theory of Economic Development: An Inquiry Into Profits, Capital, Credit, Interest, and the Business Cycle. Transaction Publishers: Piscataway, NJ.

Singh J. 2005. Collaborative networks as determinants of knowledge diffusion patterns. Management Science 51 (5): 756-770. 
Singh J, Agrawal A. 2011. Recruiting for ideas: how firms exploit the prior inventions of new hires. Management Science 57 (1): 129-150.

Singh J, Fleming L. 2010. Lone inventors as sources of breakthroughs: myth or reality? Management Science 56 (1): 41-56.

Sørensen JB, Stuart TE. 2000. Aging, obsolescence, and organizational innovation. Administrative Science Quarterly 45 (1): 81-112.

Srikanth K, Puranam P. 2014. The firm as a coordination system: evidence from software services offshoring. Organization Science 25 (4): 1253-1271.

Srikanth K, Puranam P. 2011. Integrating distributed work: comparing task design, communication, and tacit coordination mechanisms. Strategic Management Journal 32 (8): 849-875.

Stuart TE, Podolny JM. 1996. Local search and the evolution of technological capabilities. Strategic Management Journal 17 (S1): 21-38.

Taylor A, Greve HR. 2006. Superman or the fantastic four? knowledge combination and experience in innovative teams. Academy of Management Journal 49 (4): 723-740.

Teece DJ, Pisano G, Shuen A. 1997. Dynamic capabilities and strategic management. Strategic Management Journal 18 (7): 509-533.

Thompson J. 1967. Organizations in Action: Social Science Bases of Administrative Theory. Classics in Organization and Management Series. Transaction Publishers: Piscataway, NJ.

Toh PK, Polidoro F. 2013. A competition-based explanation of collaborative invention within the firm. Strategic Management Journal 34 (10): 1186-1208.

Trajtenberg M. 1990. A penny for your quotes: patent citations and the value of innovations. RAND Journal of Economics 21 (1): 172-187.

Weitzman ML. 1998. Recombinant growth. Quarterly Journal of Economics 113 (2): 331-360.

Williams KY, O'Reilly CA. 1998. Demography and diversity in organizations: a review of 40 years of research. Research in Organizational Behavior 20 : 77-140.

Winter SG. 1987. Knowledge and competence as strategic assets. In The Competitive Challenge: Strategies for Industrial Innovation and Renewal, Teece DJ (ed). Ballinger: Cambridge, MA; $159-184$

Wuchty S, Jones BF, Uzzi B. 2007. The increasing dominance of teams in production of knowledge. Science 316 (5827): 1036-1039.

Yayavaram S, Ahuja G. 2008. Decomposability in knowledge structures and its impact on the usefulness of inventions and knowledge-base malleability. Administrative Science Quarterly 53 (2): 333-362. 
Figure 1. Across-Team Diversity vs. Within-Team Diversity

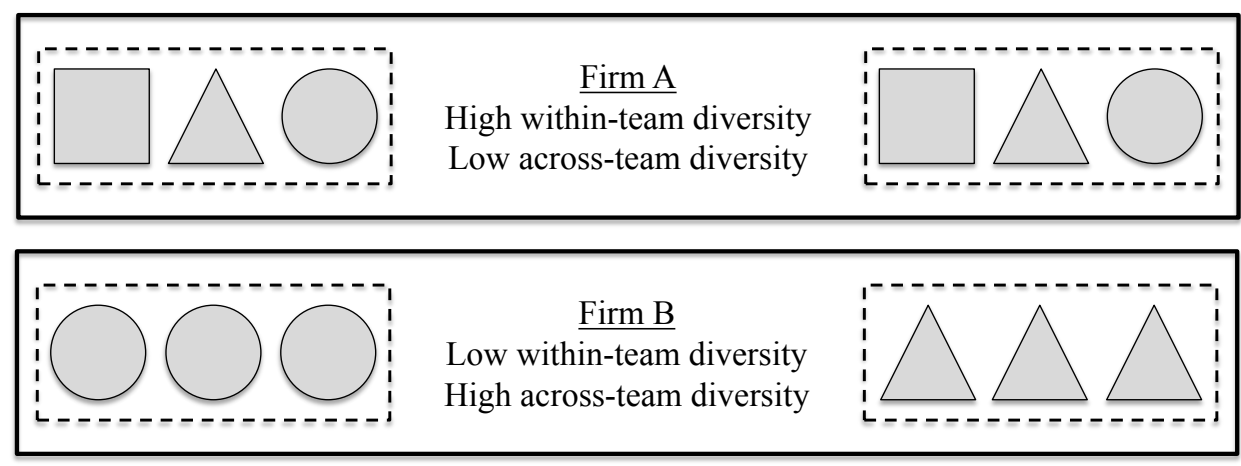

In the figure above dashed lines represent team boundaries and solid lines represent firm boundaries. Shapes represent particular types of inventors on a team. Two alternate firm-level approaches to organizing inventors on a team are depicted.

Figure 2. Predicted Forward Citations (4Y) on Moderated Main Independent Variables
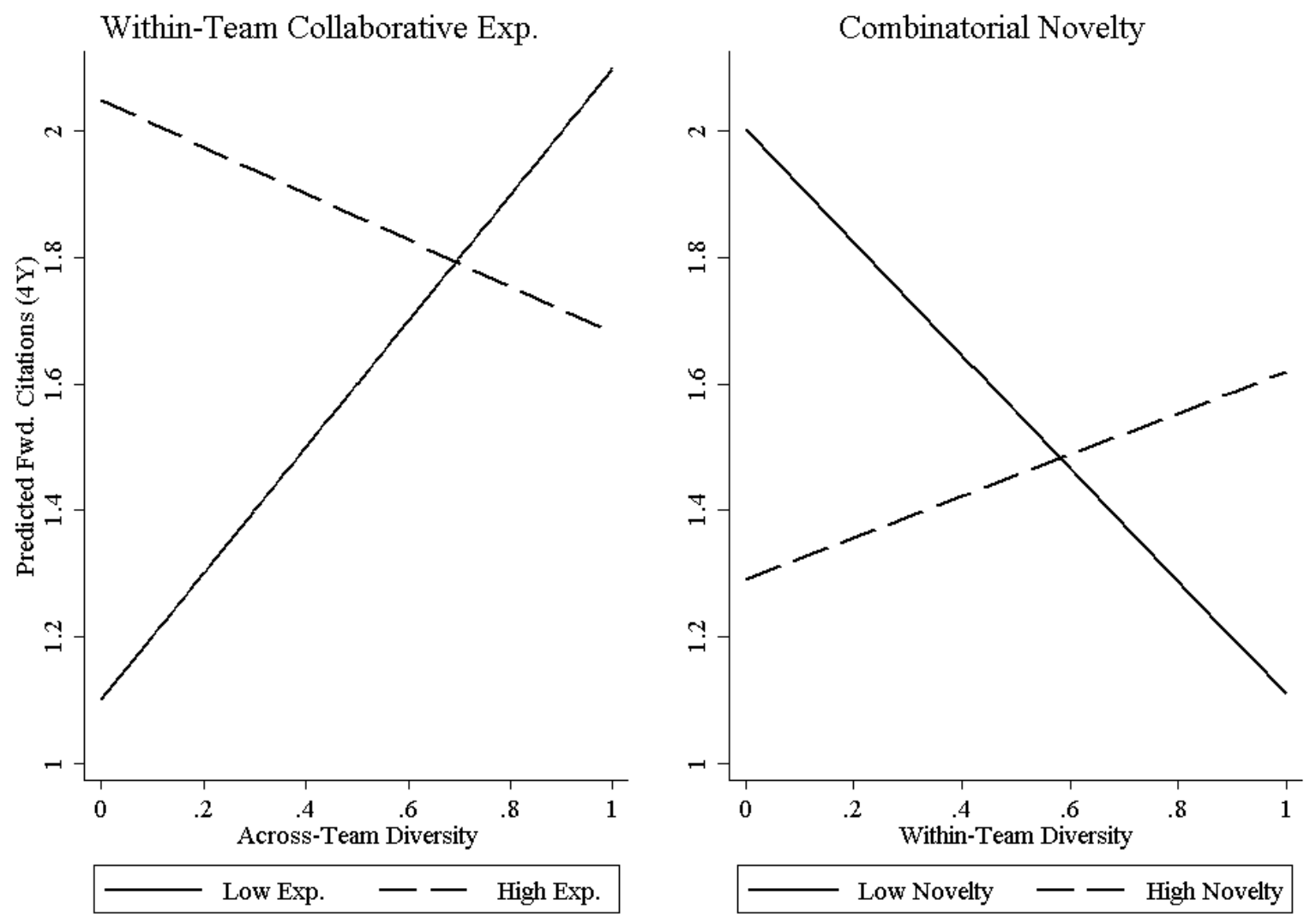
Table 1. Summary Statistics and Variable Definitions, Firm-Year Level of Analysis

\begin{tabular}{|c|c|c|c|}
\hline VARIABLE & DEFINITION & MEAN & S.D. \\
\hline \multicolumn{4}{|l|}{ Dependent variable } \\
\hline Forward citations (4Y) & $\begin{array}{l}\text { Total forward citations within a four-year window to current } \\
\text { firm-year patents }\end{array}$ & 5.14 & 21.46 \\
\hline \multicolumn{4}{|l|}{ Main independent variables } \\
\hline (1) Across-team diversity & $\begin{array}{l}\text { Average angular distance in technology class experience } \\
\text { between patent teams }\end{array}$ & 0.12 & 0.23 \\
\hline (2) Within-team diversity & $\begin{array}{l}\text { Average angular distance in technology class experience } \\
\text { between inventors on a patent team, averaged over teams }\end{array}$ & 0.20 & 0.18 \\
\hline \multicolumn{4}{|l|}{ Moderators } \\
\hline $\begin{array}{l}\text { (3) Within-team collaborative } \\
\text { experience }\end{array}$ & $\begin{array}{l}\text { Average joint prior patenting experience between dyads of } \\
\text { inventors on the same patent team }\end{array}$ & 1.26 & 2.52 \\
\hline (4) Combinatorial novelty & $\begin{array}{l}\text { Recombination of infrequently combined technological } \\
\text { components }\end{array}$ & 0.22 & 0.30 \\
\hline \multicolumn{4}{|l|}{ Inventor team controls } \\
\hline (5) Team patenting experience & Average patenting experience of teams in a firm & 9.81 & 10.72 \\
\hline (6) Team fwd. citation experience & $\begin{array}{l}\text { Average forward citations within a four-year window to } \\
\text { patents by teams in a firm }\end{array}$ & 29.18 & 70.28 \\
\hline (7) Team class experience & Average class experience of teams in a firm & 4.70 & 3.30 \\
\hline \multicolumn{4}{|l|}{ Firm patenting controls } \\
\hline (8) Patent count & Number of patents in a firm-year & 2.24 & 7.93 \\
\hline (9) Inventor count & Number of inventors in a firm-year & 4.46 & 12.61 \\
\hline (10) Class span & Number of classes in a firm-year & 0.80 & 1.47 \\
\hline (11) Total collaborative experience & Average joint patenting experience between all inventors & 0.74 & 1.56 \\
\hline \multicolumn{4}{|l|}{ Corporate controls } \\
\hline (12) Age & Years since firm founding & 8.42 & 6.12 \\
\hline (13) VC inflows stock & Cumulative venture capital investment into the firm & 16.39 & 27.88 \\
\hline (14) Strategic alliance stock & Stock count of strategic alliances & 10.39 & 17.91 \\
\hline (15) Active product (all stages) & Indicator for an active product under FDA review & 0.65 & 0.48 \\
\hline (16) Post-IPO & Indicator for IPO in firm history & 0.32 & 0.47 \\
\hline (17) Post-M\&A & Indicator for M\&A in firm history & 0.15 & 0.35 \\
\hline
\end{tabular}

Table 2. Pairwise Correlation Matrix of Independent Variables

\begin{tabular}{|c|c|c|c|c|c|c|c|c|c|c|c|c|c|c|c|c|c|}
\hline & (1) & (2) & (3) & (4) & (5) & (6) & (7) & (8) & (9) & (10) & (11) & (12) & (13) & (14) & (15) & (16) & (17) \\
\hline (1) & 1.00 & & & & & & & & & & & & & & & & \\
\hline (2) & 0.05 & 1.00 & & & & & & & & & & & & & & & \\
\hline (3) & 0.11 & -0.11 & 1.00 & & & & & & & & & & & & & & \\
\hline (4) & 0.02 & 0.02 & 0.06 & 1.00 & & & & & & & & & & & & & \\
\hline (5) & -0.03 & 0.07 & 0.60 & 0.07 & 1.00 & & & & & & & & & & & & \\
\hline (6) & -0.05 & 0.03 & 0.29 & 0.01 & 0.57 & 1.00 & & & & & & & & & & & \\
\hline (7) & 0.04 & 0.37 & 0.29 & 0.01 & 0.53 & 0.25 & 1.00 & & & & & & & & & & \\
\hline (8) & 0.20 & -0.04 & 0.47 & 0.02 & 0.36 & 0.14 & 0.10 & 1.00 & & & & & & & & & \\
\hline (9) & 0.30 & -0.02 & 0.38 & 0.02 & 0.19 & 0.04 & 0.16 & 0.77 & 1.00 & & & & & & & & \\
\hline (10) & 0.45 & 0.03 & 0.55 & 0.03 & 0.25 & 0.11 & 0.19 & 0.71 & 0.79 & 1.00 & & & & & & & \\
\hline (11) & -0.07 & -0.08 & 0.77 & 0.03 & 0.31 & 0.18 & 0.24 & 0.08 & 0.10 & 0.25 & 1.00 & & & & & & \\
\hline (12) & 0.02 & -0.10 & 0.06 & 0.11 & 0.11 & -0.02 & 0.10 & 0.08 & 0.15 & 0.09 & 0.02 & 1.00 & & & & & \\
\hline (13) & 0.07 & 0.03 & 0.20 & 0.06 & 0.16 & 0.00 & 0.23 & 0.09 & 0.14 & 0.20 & 0.14 & 0.11 & 1.00 & & & & \\
\hline (14) & 0.21 & -0.05 & 0.22 & 0.11 & 0.15 & -0.01 & 0.11 & 0.31 & 0.46 & 0.40 & 0.06 & 0.43 & 0.15 & 1.00 & & & \\
\hline (15) & 0.05 & -0.11 & -0.02 & -0.12 & -0.11 & -0.11 & -0.14 & 0.04 & 0.07 & 0.06 & -0.04 & 0.34 & -0.14 & 0.14 & 1.00 & & \\
\hline (16) & 0.15 & -0.04 & 0.21 & 0.00 & 0.09 & -0.05 & 0.10 & 0.19 & 0.24 & 0.30 & 0.12 & 0.39 & 0.21 & 0.45 & 0.27 & 1.00 & \\
\hline (17) & -0.03 & -0.03 & -0.06 & 0.07 & 0.03 & 0.00 & -0.03 & -0.06 & -0.06 & -0.09 & -0.04 & 0.30 & 0.06 & 0.07 & -0.09 & 0.15 & 1.00 \\
\hline
\end{tabular}




\section{Table 3. Average Effects of Across-Team and Within-Team Diversity Firm-Year Level of Analysis}

\begin{tabular}{|c|c|c|c|}
\hline & \multicolumn{3}{|c|}{$\begin{array}{c}\text { Conditional Firm Fixed Effects Poisson Estimation } \\
\text { Reported Coefficients are Incidence Rate Ratios with } \\
\text { (Robust Standard Errors) } \\
\text { Dependent Variable: Forward Citations (4Y) }\end{array}$} \\
\hline & (3-1) & $(3-2)$ & (3-3) \\
\hline Across-team diversity & $\begin{array}{l}2.033 * * * \\
(0.336)\end{array}$ & $\begin{array}{l}1.907 * * * \\
(0.285)\end{array}$ & $\begin{array}{l}1.583 * * * \\
(0.239)\end{array}$ \\
\hline Within-team diversity & $\begin{array}{c}0.515^{*} \\
(0.182)\end{array}$ & $\begin{array}{l}0.475 * * * \\
(0.132)\end{array}$ & $\begin{array}{l}0.377^{* * *} \\
(0.110)\end{array}$ \\
\hline Team patenting experience & & $\begin{array}{c}1.007 \\
(0.005)\end{array}$ & $\begin{array}{c}0.993 \\
(0.007)\end{array}$ \\
\hline Team fiwd. citation experience & & $\begin{array}{c}1.000 \\
(0.001)\end{array}$ & $\begin{array}{c}1.002 \\
(0.001)\end{array}$ \\
\hline Team class experience & & $\begin{array}{l}1.055^{* * * *} \\
(0.018)\end{array}$ & $\begin{array}{l}1.063^{* * *} \\
(0.020)\end{array}$ \\
\hline Patent count & & & $\begin{array}{l}1.006^{* * *} \\
(0.001)\end{array}$ \\
\hline Inventor count & & & $\begin{array}{c}0.998 \\
(0.002)\end{array}$ \\
\hline Class span & & & $\begin{array}{l}1.092^{* *} \\
(0.043)\end{array}$ \\
\hline Total collaborative experience & & & $\begin{array}{l}0.929^{* *} \\
(0.030)\end{array}$ \\
\hline L $A g e$ & & & $\begin{array}{c}0.597^{* *} \\
(0.151)\end{array}$ \\
\hline L VC inflows stock & & & $\begin{array}{c}0.909 \\
(0.068)\end{array}$ \\
\hline L Strategic alliances stock & & & $\begin{array}{l}1.362^{* *} \\
(0.172)\end{array}$ \\
\hline Active product (all stages) & & & $\begin{array}{c}1.105 \\
(0.155)\end{array}$ \\
\hline Post-IPO & & & $\begin{array}{c}1.020 \\
(0.144) \\
\end{array}$ \\
\hline Post-M\&A & & & $\begin{array}{c}0.693^{* *} \\
(0.117)\end{array}$ \\
\hline Firm FE & Yes & Yes & Yes \\
\hline Year FE & Yes & Yes & Yes \\
\hline Log Pseudolikelihood & -19855.1 & -14824.3 & -11744.8 \\
\hline Observations & 4386 & 2546 & 2283 \\
\hline
\end{tabular}

Coefficients are incidence rate ratios. Robust standard errors indicated in parentheses. *, ** or *** indicates statistical significance at the $10 \%, 5 \%$, and $1 \%$ levels. The natural logarithm of a variable $\mathrm{X}$ is denoted $\mathrm{L} \mathrm{X}$. 
Table 4. Moderating Effects: Within-Team Collaborative Experience and Combinatorial Novelty Firm-Year Level of Analysis

\begin{tabular}{|c|c|c|c|c|c|}
\hline & \multicolumn{5}{|c|}{$\begin{array}{c}\text { Conditional Firm Fixed Effects Poisson Estimation } \\
\text { Reported Coefficients are Incidence Rate Ratios with (Robust Standard Errors) } \\
\text { Dependent Variable: Forward Citations (4Y) }\end{array}$} \\
\hline & \multicolumn{2}{|c|}{ Collaborative Experience } & \multicolumn{2}{|c|}{ Combinatorial Novelty } & \multirow{2}{*}{$\begin{array}{c}\text { Full Model } \\
\text { (4-5) }\end{array}$} \\
\hline & $(4-1)$ & $(4-2)$ & (4-3) & $(4-4)$ & \\
\hline Across-team diversity & $\begin{array}{l}1.522 * * * \\
(0.219)\end{array}$ & $\begin{array}{l}2.590 * * * \\
(0.372)\end{array}$ & $\begin{array}{l}1.567 * * * \\
(0.231)\end{array}$ & $\begin{array}{l}1.491 * * \\
(0.265) \\
\end{array}$ & $\begin{array}{l}2.198 * * * \\
(0.377)\end{array}$ \\
\hline Within-team diversity & $\begin{array}{l}0.528 * * \\
(0.144)\end{array}$ & $\begin{array}{l}0.434 * * * \\
(0.128)\end{array}$ & $\begin{array}{l}0.374 * * * \\
(0.106)\end{array}$ & $\begin{array}{l}0.282 * * * \\
(0.079)\end{array}$ & $\begin{array}{l}0.297 * * * \\
(0.097)\end{array}$ \\
\hline Within-team collaborative experience & $\begin{array}{l}1.131 * * * \\
(0.026)\end{array}$ & $\begin{array}{l}1.156^{* * *} \\
(0.033)\end{array}$ & & & $\begin{array}{l}1.160 * * * \\
(0.032)\end{array}$ \\
\hline $\begin{array}{l}\text { Across-team diversity } x \\
\text { Within-team collaborative experience }\end{array}$ & & $\begin{array}{l}0.792 * * * \\
(0.037)\end{array}$ & & & $\begin{array}{l}0.789 * * * \\
(0.038)\end{array}$ \\
\hline $\begin{array}{l}\text { Within-team diversity } x \\
\text { Within-team collaborative experience }\end{array}$ & & $\begin{array}{l}1.063 \\
(0.125) \\
\end{array}$ & & & $\begin{array}{c}1.084 \\
(0.131) \\
\end{array}$ \\
\hline Combinatorial novelty & & & $\begin{array}{l}0.565^{* *} \\
(0.141)\end{array}$ & $\begin{array}{l}0.363 * * * \\
(0.136)\end{array}$ & $\begin{array}{l}0.261^{* * *} \\
(0.109)\end{array}$ \\
\hline $\begin{array}{l}\text { Across-team diversity } x \\
\text { Combinatorial novelty }\end{array}$ & & & & $\begin{array}{c}1.379 \\
(0.810)\end{array}$ & $\begin{array}{c}2.614 \\
(1.676)\end{array}$ \\
\hline $\begin{array}{l}\text { Within-team diversity } x \\
\text { Combinatorial novelty }\end{array}$ & & & & $\begin{array}{l}4.731 * \\
(4.220)\end{array}$ & $\begin{array}{l}7.310 * * \\
(6.440)\end{array}$ \\
\hline Team patenting experience & $\begin{array}{l}0.960 * * * \\
(0.008)\end{array}$ & $\begin{array}{l}0.957 * * * \\
(0.008)\end{array}$ & $\begin{array}{c}0.994 \\
(0.007)\end{array}$ & $\begin{array}{c}0.994 \\
(0.007)\end{array}$ & $\begin{array}{l}0.957 * * * \\
(0.008)\end{array}$ \\
\hline Team fwd. citation experience & $\begin{array}{l}1.004 * * * \\
(0.001)\end{array}$ & $\begin{array}{l}1.004 * * * \\
(0.001)\end{array}$ & $\begin{array}{c}1.002 \\
(0.001)\end{array}$ & $\begin{array}{c}1.002 \\
(0.001)\end{array}$ & $\begin{array}{l}1.004 * * * \\
(0.001)\end{array}$ \\
\hline Team class experience & $\begin{array}{l}1.077 * * * \\
(0.020)\end{array}$ & $\begin{array}{l}1.077 * * * \\
(0.020)\end{array}$ & $\begin{array}{l}1.060^{* * *} \\
(0.019)\end{array}$ & $\begin{array}{l}1.062 * * * \\
(0.019)\end{array}$ & $\begin{array}{l}1.076^{* * *} \\
(0.020)\end{array}$ \\
\hline Patent count & $\begin{array}{l}1.005 * * * \\
(0.001)\end{array}$ & $\begin{array}{l}1.004 * * * \\
(0.001)\end{array}$ & $\begin{array}{l}1.006^{* * *} \\
(0.001)\end{array}$ & $\begin{array}{l}1.006^{* * *} \\
(0.001)\end{array}$ & $\begin{array}{l}1.004 * * * \\
(0.001)\end{array}$ \\
\hline Inventor count & $\begin{array}{c}1.000 \\
(0.002)\end{array}$ & $\begin{array}{c}1.001 \\
(0.002)\end{array}$ & $\begin{array}{c}0.998 \\
(0.002)\end{array}$ & $\begin{array}{c}0.998 \\
(0.002)\end{array}$ & $\begin{array}{c}1.001 \\
(0.002)\end{array}$ \\
\hline Class span & $\begin{array}{l}1.068 * * \\
(0.030) \\
\end{array}$ & $\begin{array}{l}1.072 * * \\
(0.033) \\
\end{array}$ & $\begin{array}{l}1.091^{* *} \\
(0.043)\end{array}$ & $\begin{array}{l}1.091^{* *} \\
(0.043)\end{array}$ & $\begin{array}{l}1.069 * * \\
(0.032)\end{array}$ \\
\hline Total collaborative experience & $\begin{array}{l}0.808 * * * \\
(0.039)\end{array}$ & $\begin{array}{l}0.788^{* * *} \\
(0.040)\end{array}$ & $\begin{array}{l}0.927^{* *} \\
(0.030)\end{array}$ & $\begin{array}{l}0.926^{* *} \\
(0.029)\end{array}$ & $\begin{array}{l}0.780^{* * *} \\
(0.039) \\
\end{array}$ \\
\hline L Age & $\begin{array}{c}0.581^{*} \\
(0.164)\end{array}$ & $\begin{array}{c}0.583^{*} \\
(0.165)\end{array}$ & $\begin{array}{l}0.592 * * \\
(0.146)\end{array}$ & $\begin{array}{l}0.597 * * \\
(0.144)\end{array}$ & $\begin{array}{l}0.587 * * \\
(0.156)\end{array}$ \\
\hline L VC inflows stock & $\begin{array}{c}0.874^{*} \\
(0.065)\end{array}$ & $\begin{array}{l}0.856^{* *} \\
(0.062)\end{array}$ & $\begin{array}{c}0.912 \\
(0.067)\end{array}$ & $\begin{array}{c}0.916 \\
(0.066)\end{array}$ & $\begin{array}{l}0.864 * * \\
(0.060)\end{array}$ \\
\hline L Strategic alliances stock & $\begin{array}{l}1.337 * * \\
(0.170)\end{array}$ & $\begin{array}{l}1.319 * * \\
(0.173)\end{array}$ & $\begin{array}{l}1.372 * * \\
(0.173)\end{array}$ & $\begin{array}{l}1.377 * * \\
(0.174)\end{array}$ & $\begin{array}{l}1.333 * * \\
(0.175)\end{array}$ \\
\hline Active product (all stages) & $\begin{array}{c}1.064 \\
(0.135)\end{array}$ & $\begin{array}{c}1.059 \\
(0.136)\end{array}$ & $\begin{array}{c}1.086 \\
(0.153)\end{array}$ & $\begin{array}{c}1.078 \\
(0.152)\end{array}$ & $\begin{array}{c}1.030 \\
(0.132)\end{array}$ \\
\hline Post-IPO & $\begin{array}{c}1.012 \\
(0.148)\end{array}$ & $\begin{array}{c}0.998 \\
(0.139)\end{array}$ & $\begin{array}{c}1.020 \\
(0.142)\end{array}$ & $\begin{array}{c}1.007 \\
(0.138)\end{array}$ & $\begin{array}{c}0.983 \\
(0.130)\end{array}$ \\
\hline Post-M\&A & $\begin{array}{l}0.646^{* *} \\
(0.130)\end{array}$ & $\begin{array}{l}0.688^{* *} \\
(0.120)\end{array}$ & $\begin{array}{l}0.692 * * \\
(0.116)\end{array}$ & $\begin{array}{l}0.695 * * \\
(0.117)\end{array}$ & $\begin{array}{l}0.701^{* *} \\
(0.120)\end{array}$ \\
\hline Firm FE & Yes & Yes & Yes & Yes & Yes \\
\hline Year FE & Yes & Yes & Yes & Yes & Yes \\
\hline Log Pseudolikelihood & -11109.1 & -10918.5 & -11679.2 & -11644.0 & -10782.8 \\
\hline Observations & 2283 & 2283 & 2279 & 2279 & 2279 \\
\hline
\end{tabular}

Coefficients are incidence rate ratios. Robust standard errors indicated in parentheses. *, ** or *** indicates statistical significance at the $10 \%, 5 \%$, and $1 \%$ levels. The natural logarithm of a variable $\mathrm{X}$ is denoted $\mathrm{L} \mathrm{X}$. 
Table 5A. Coarsened Exact Matching (CEM) Balancing

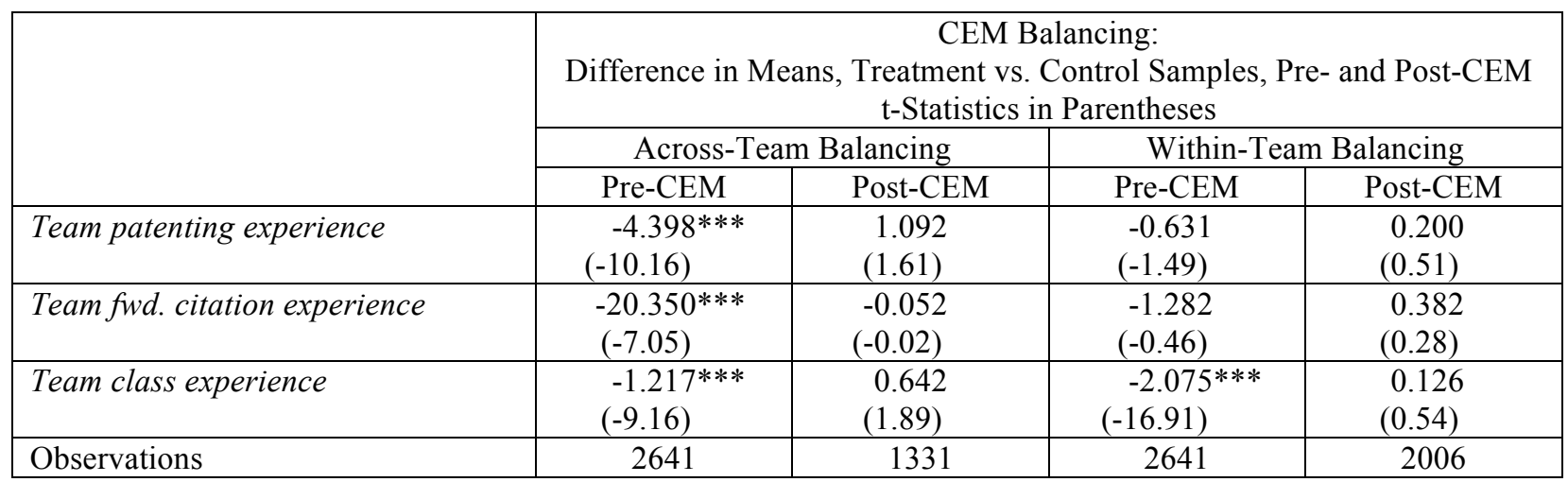

Values in table are differences in means; t-statistics in parentheses. *** indicates t-statistic is significant at the $1 \%$ level.

Table 5B. CEM Regressions

\begin{tabular}{|c|c|c|c|c|}
\hline & \multicolumn{4}{|c|}{$\begin{array}{c}\text { Firm Fixed Effects OLS Regressions with Robust Standard Errors } \\
\text { Dependent Variable: L }[1+\text { Forward Citations (4Y)] }\end{array}$} \\
\hline & \multicolumn{2}{|c|}{ Across-Team Balancing } & \multicolumn{2}{|c|}{ Within-Team Balancing } \\
\hline & $(4-1)$ & $(4-2)$ & $(4-3)$ & $(4-4)$ \\
\hline Across-team diversity & $\begin{array}{l}0.449 * * * \\
(0.138)\end{array}$ & $\begin{array}{r}0.451 * \\
(0.233)\end{array}$ & $\begin{array}{l}0.436 * * * \\
(0.099)\end{array}$ & $\begin{array}{l}0.900 * * * \\
(0.154)\end{array}$ \\
\hline Within-team diversity & $\begin{array}{l}-0.155 \\
(0.167) \\
\end{array}$ & $\begin{array}{l}-0.288 \\
(0.247)\end{array}$ & $\begin{array}{l}-0.397 * * * \\
(0.153)\end{array}$ & $\begin{array}{l}-0.506 * * \\
(0.229)\end{array}$ \\
\hline Within-team collaborative experience & & $\begin{array}{l}-0.019 \\
(0.040)\end{array}$ & & $\begin{array}{l}0.128 * * * \\
(0.027)\end{array}$ \\
\hline $\begin{array}{l}\text { Across-team diversity } x \\
\text { Within-team collaborative experience }\end{array}$ & & $\begin{array}{l}-0.050 \\
(0.092)\end{array}$ & & $\begin{array}{l}-0.243 * * * \\
(0.049)\end{array}$ \\
\hline $\begin{array}{l}\text { Within-team diversity } x \\
\text { Within-team collaborative experience }\end{array}$ & & $\begin{array}{l}-0.077 \\
(0.092)\end{array}$ & & $\begin{array}{l}-0.125 \\
(0.082)\end{array}$ \\
\hline Combinatorial novelty & & $\begin{array}{l}-0.360 * * \\
(0.156)\end{array}$ & & $\begin{array}{l}-0.619 * * * \\
(0.152)\end{array}$ \\
\hline $\begin{array}{r}\text { Across-team diversity } x \\
\text { Combinatorial novelty } \\
\end{array}$ & & $\begin{array}{c}0.434 \\
(0.504) \\
\end{array}$ & & $\begin{array}{l}-0.263 \\
(0.390) \\
\end{array}$ \\
\hline $\begin{array}{l}\text { Within-team diversity } x \\
\text { Combinatorial novelty }\end{array}$ & & $\begin{array}{l}1.175^{* *} \\
(0.534)\end{array}$ & & $\begin{array}{l}2.148 * * * \\
(0.525)\end{array}$ \\
\hline Inventor team controls & Yes & Yes & Yes & Yes \\
\hline Firm patenting controls & Yes & Yes & Yes & Yes \\
\hline Corporate controls & Yes & Yes & Yes & Yes \\
\hline Constant term & Yes & Yes & Yes & Yes \\
\hline Firm FE & Yes & Yes & Yes & Yes \\
\hline Year FE & Yes & Yes & Yes & Yes \\
\hline Adjusted R-Squared & 0.625 & 0.625 & 0.694 & 0.704 \\
\hline Observations & 1246 & 1242 & 1820 & 1818 \\
\hline
\end{tabular}

Robust standard errors indicated in parentheses. *,** or *** indicates statistical significance at the $10 \%, 5 \%$, and $1 \%$ levels. The natural logarithm of a variable $\mathrm{X}$ is denoted $\mathrm{L} \mathrm{X}$. 